Case Reports in
Gastroenterology
Case Rep Gastroenterol 2020;14:483-490

DOI: 10.1159/000509542

Published online: October 15, 2020

(c) 2020 The Author(s)

Published by S. Karger AG, Basel www.karger.com/crg

This article is licensed under the Creative Commons Attribution-NonCommercial 4.0 International License (CC BY-NC) (http://www.karger.com/Services/OpenAccessLicense). Usage and distribution for commercial purposes requires written permission.

\title{
Ascending Colon Schwannoma Surgically Treated after Accurate Preoperative Diagnosis
}

\author{
Yohei Kojimaa, ${ }^{a}$ Takashi Yamaguchi ${ }^{a}$ Satoshi Taguchi ${ }^{a} \quad$ Eri Kondo ${ }^{a}$ \\ Masaaki Yokoyama $^{a}$ Saito Shirayama ${ }^{a}$ Takashi Nikaido $^{b}$ \\ Osamu Yanagida ${ }^{a}$ \\ aDepartment of Surgery, Kosei Hospital, Tokyo, Japan; ${ }^{b}$ Department of Diagnostic \\ Pathology, Kosei Hospital, Tokyo, Japan; 'Department of Surgery, Kyorin University \\ Hospital, Tokyo, Japan
}

\section{Keywords}

Colonic submucosal tumor · Schwannoma - Surgical treatment

\begin{abstract}
Colorectal schwannomas are rare and usually benign gastrointestinal mesenchymal tumors. However, these tumors are often overtreated, possibly owing to misleading malignant potential. To our knowledge, there have been no previous reports of ascending colon schwannoma preoperatively diagnosed as benign schwannoma. Herein, we report a case of ascending colon schwannoma accurately diagnosed by endoscopic biopsy and successfully treated by wedge resection. The patient was a 76-year-old woman with complaints of bloody stool. She had no relevant past medical history. Radiological findings revealed a protruded mass in the ascending colon, and colonoscopy revealed a submucosal tumor measuring approximately $3 \mathrm{~cm}$ in diameter with a reddish and uneven surface. Histological and immunohistochemical analysis for vimentin and S100 protein of the specimen obtained by endoscopic biopsy confirmed the diagnosis of schwannoma. Thus, we performed laparoscopy-assisted endoscopic full-thickness resection of the ascending colon wall, as appropriate for a benign soft tissue tumor. The postoperative course has been uneventful for 2 years. This case demonstrates that colonic schwannoma can be successfully treated with adequate resection if an accurate preoperative diagnosis is made, thereby avoiding overtreatment, such as surgery for colorectal tumor including lymph
\end{abstract}




\section{Case Reports in Gastroenterology}

Case Rep Gastroenterol 2020;14:483-490 DOI: $10.1159 / 000509542$

(c) 2020 The Author(s). Published by S. Karger AG, Basel www.karger.com/crg

Kojima et al.: A Case of Ascending Colon Schwannoma

node dissection. Preoperatively diagnosed schwannomas should be treated by wedge resection, with postoperative pathological findings confirming the presence or absence of malignancy. Additional resection should be considered for very rare cases of coexisting malignant tissue.

(c) 2020 The Author(s)

Published by S. Karger AG, Basel

\section{Introduction}

Verocay [1] first described a rare benign neoplasm of ectodermic origin growing from the neural sheath in 1910. Schwannomas of soft tissues are usually slow-growing benign tumors. They are equally seen in both sexes and are mostly found after the sixth and seventh decades of life, but can appear at any age [2]. Colorectal schwannomas are extremely rare; there have been only 96 reported cases thus far, and $96.9 \%$ of them were considered benign [2,3]. When planning surgical treatment for these patients, adequate minimally invasive surgery should be considered. However, in the majority of cases (74\%), the diagnosis was confirmed postoperatively, while endoscopically only in $24 \%$. It is difficult to make an accurate preoperative diagnosis by biopsy because schwannomas are submucosal lesions [4]. Hence, in many cases, benign schwannomas have been overtreated by colectomy with peripheral lymph node dissection instead of local resection. Among the reported cases, excluding those treated by endoscopic resection, surgical resection was performed in 58 cases; classical segmental procedures in $55(94.8 \%)$, whereas wedge resection only in $3(5.2 \%)$ cases [2]. Moreover, in the 3 cases where wedge resection was performed, the diagnosis was confirmed postoperatively, while in the 6 cases where the tumors were diagnosed as benign, classical segmental resection had been performed. It has been reported that schwannomas may co-exist with malignant peripheral nerve sheath tumors [5]. Thus, although schwannomas are usually benign, misleading malignant potential might be why these tumors are often overtreated.

To the best of our knowledge, there have been no previous reports of ascending colon schwannoma preoperatively diagnosed as benign schwannoma and treated by laparoscopyassisted wedge resection. Herein, we report a case of ascending colon schwannoma accurately diagnosed by endoscopic biopsy and successfully treated by wedge resection, along with a literature review.

\section{Case Presentation}

A 76-year-old woman presented to our outpatient clinic with a 1-year history of intermittent bloody stool. She had no comorbidities. Her history and physical examination indicated lower gastrointestinal bleeding. The laboratory findings included: leucocytes $7,300 / \mu \mathrm{L}$, hemoglobin $9.9 \mathrm{~g} / \mathrm{dL}$, CA-19.9 3.0 U/mL, and carcinoembryonic antigen $1.7 \mathrm{ng} / \mathrm{mL}$. Abdominal ultrasound revealed a mass, but its location could not be clearly defined. Abdominal computed tomography revealed a mass in the ascending colon, approximately $3 \mathrm{~cm}$ in size, which was suspected to be malignant. Intraluminal protrusion with narrowing of the lumen and wall thickening was observed. Lymph node, liver, or lung metastases were not detected. Contrast enema examination showed a steep edged mass shadow in the ascending colon with clearly defined boundaries (Fig. 1). Colonoscopy revealed a protruding mass in the ascending colon with a rough, eroded surface covered by a white coat, resembling a protruding type carcinoma, and multiple biopsies were performed (Fig. 2). On endoscopic ultrasonography, there was no tumor mobility and no clear boundary between the tumor and the intestinal wall. 


\section{Case Reports in Gastroenterology}

\begin{tabular}{l|l}
\hline Case Rep Gastroenterol 2020;14:483-490 \\
\hline DOI: 10.1159/000509542 & $\begin{array}{l}\text { @ 2020 The Author(s). Published by S. Karger AG, Basel } \\
\text { www.karger.com/crg }\end{array}$ \\
\hline
\end{tabular}

Kojima et al.: A Case of Ascending Colon Schwannoma

Histopathologic analysis of the preoperative endoscopic biopsy specimens revealed colonic schwannoma. Therefore, local resection of the ascending colon was planned.

After confirming intraoperatively that the tumor was fixed on the muscle layer, we performed full-thickness wedge resection of the ascending colon tumor under laparoscopic assistance. Following ascending colon mobilization, full-thickness tumor excision was performed through minilaparotomy, with at least 5-mm margins around the tumor. The ascending colon opening was closed via suturing.

The postoperative course was uneventful, without bowel obstruction, surgical site infection, or pneumonia. The patient was started on oral diet 2 days after surgery. She was discharged on the eighth postoperative day without any complaints, with a recommendation for outpatient control. There has been no recurrence during the 2-year follow-up.

\section{Histopathological Findings}

\section{Biopsy Specimens}

The histopathological diagnosis of schwannoma was made based on histological and immunohistochemical analysis of the biopsy specimens (Fig. 3).

After hematoxylin and eosin staining, all specimens revealed inflamed erosive colon mucosa with spindle cell proliferation in the deeper lamina propria region containing woven nests of compact bundles of slender, wavy spindle cells admixed with a lymphocyte-rich stroma. The spindle cells also formed compact fascicles, occasionally aligning in rows. Individual cells had a distinct eosinophilic cytoplasm and dark fusiform nuclei that varied in shape and size. When tumor bundles were cut transversely, the cells appeared round and epithelioid. Mitotic activity was minimal $(1 / 50)$. These findings indicated benign schwannoma. The differential diagnosis included gastrointestinal stromal tumor, smooth muscle tumor, and other spindle cell soft tissue tumors.

All spindle-shaped tumor cells were strongly and globally positive for vimentin and S100 protein, the latter with both nuclear and cytoplasmic staining, and negative for CD117 (KIT), CD34, and smooth muscle-related antigens (smooth muscle actin, desmin, calponin, and hcaldesmon). The Ki-67 labeling index was less than $1 \%$.

\section{Resected Specimen}

The firm and rubbery tumor involved the colon transmurally (Fig. 3b). On gross inspection, the tumor was a circumscribed but unencapsulated ovoid nodular mass with a polypoid intraluminal component measuring $3 \times 3 \times 1.7 \mathrm{~cm}$ in size. Wide-spread mucosal erosion was grossly visible. The cut surface was yellowish without myxoid degeneration or tumor necrosis. The histological and immunohistochemical findings, including the Ki-67 labeling index, were the same as for the biopsy specimens. Additionally, tumor nuclear palisading and a discontinuous lymphoid cuff were also detected.

\section{Discussion/Conclusion}

In the present case, the tumor was preoperatively diagnosed as a benign schwannoma based on histological and immunohistochemical analysis of the biopsy specimens, which enabled timely planning of wedge resection and avoiding overtreatment by classical segmental resection. 


\section{Case Reports in Gastroenterology}

Case Rep Gastroenterol 2020;14:483-490 DOI: $10.1159 / 000509542$

c) 2020 The Author(s). Published by S. Karger AG, Basel www.karger.com/crg

Kojima et al.: A Case of Ascending Colon Schwannoma

In a recent review of 70 articles reporting 95 cases of colorectal schwannoma [2], the patients' mean age was 61.2 (range, 14-95) years and 22.9\% of them had bloody stool, while $36.4 \%$ were asymptomatic. The tumor size ranged from 0.3 to $28 \mathrm{~cm}$, with a median of $3 \mathrm{~cm}$. The diagnosis of schwannoma was made on the operative specimen in the majority of cases (74\%), and by endoscopic or transanal biopsy in $24 \%$ of cases. Three patients were diagnosed with schwannoma preoperatively and underwent wedge colonic resection, but the diagnosis was confirmed postoperatively. Namely, the preoperative differential diagnosis included other diseases because of unavailable histopathological findings; the mucosal layer over the tumor interfered with the schwannoma tissue sampling [2, 6, 7]. It seems that preoperative diagnosis of schwannomas is difficult to reach because these lesions appear as submucosal tumors, meaning that the mucosal biopsy specimens would likely be normal. Inagawa et al. [8] reported that the rate of accurate preoperative diagnosis of benign schwannomas was only $15.2 \%$.

Colorectal schwannomas are described as circumscribed but unencapsulated, while peripheral soft tissue schwannomas have a distinct well-circumscribed fibrous capsule. Many colorectal schwannomas histologically interdigitate with the surrounding stroma and in many cases have a conspicuous inflammatory infiltrate including lymphocytes, eosinophils, and mast cells. Thus, larger colorectal schwannomas tend to cause wide-spreading erosion or ulceration, same as the juvenile polyp and inflammatory fibroid polyp. This is why accurate preoperative diagnosis of colonic schwannoma is difficult [4, 9-13].

In the present case, the biopsied mucosa that had erosions on colonoscopy had a spindle cell proliferative lesion in the deeper lamina propria. There have been 18 reports of benign schwannomas in the Japana Centra Revuo Medicina database during the past 10 years. Among them, necrotic or granulation tissue was observed in the biopsy specimens in $5(25 \%)$ cases, including our case. Furthermore, Miettinen et al. [14] observed ulceration in 8 of 15 spindle cell type schwannomas.

Surgical management of schwannomas depends on the tumor size, location, and histopathological pattern. Currently, complete surgical resection of the tumor with margins free of disease is the best therapeutic choice $[7,15]$. Because the risk of malignant transformation is small, broad lymph node resections are not recommended [7], and radiation therapy or chemotherapy is generally not performed. Benign schwannomas have been treated by extensive resection, including broad lymph node resection in $67.7 \%$ of cases, whereas local full-thickness resection of the colorectal wall was performed only in 3 cases (4\%). In those cases, described in the systematic review of Bohlok et al. [2], the patients were diagnosed with schwannoma preoperatively and underwent wedge colonic resection; however, histopathological diagnosis was not performed to rule out malignant potential. In the present case, we considered that extensive resection was unnecessary because malignant potential was ruled out before surgery. Ours is a rare case in that the preoperative diagnosis was useful for selecting the surgical procedure. Despite the possibility of coexisting malignancy, considering the high rate of benign nature (96\%), wedge resection should be selected for these tumors, thus avoiding overtreatment. Additional resection may be performed if the postoperative histopathological diagnosis indicates malignancy.

In conclusion, this case highlights the importance of preoperative histological diagnosis for adequate, minimally invasive surgical treatment of colorectal schwannoma. Wedge resection should be more frequently considered for colorectal schwannoma. 
Case Reports in
Gastroenterology

Case Rep Gastroenterol 2020;14:483-490

DOI: $10.1159 / 000509542$

(c) 2020 The Author(s). Published by S. Karger AG, Basel www.karger.com/crg

Kojima et al.: A Case of Ascending Colon Schwannoma

\section{Statement of Ethics}

The patient provided informed consent for publication.

\section{Conflict of Interest Statement}

The authors have no conflicts of interest to declare.

\section{Funding Sources}

No funding was received for this study.

\section{Author Contributions}

Takashi Yamaguchi, Satoshi Taguchi, Eri Kondo, Masaaki Yokoyama, Saito Shirayama, surgical support and adviser; Takashi Nikaido, study supervisor for Pathology; Osamu Yanagida, study adviser for surgery, study and manuscript supervisor. This paper is not based on a previous communication to a society or meeting.

\section{References}

1 Verocay J. Zur kenntnis der Neurofibrome. Beitr Path Anat Allg Pathol. 1910;48:1-68.

2 Bohlok A, El Khoury M, Bormans A, Galdon MG, Vouche M, El Nakadi I, et al. Schwannoma of the colon and rectum: a systematic literature review. World J Surg Oncol. 2018 Jul;16(1):125.

3 Baig MM, Patel R, Kazem MA, Khan A. Schwannoma in the ascending colon, a rare finding on surveillance colonoscopy. J Surg Case Rep. 2019 Feb;2019(2):rjz046.

4 Daimaru Y, Kido H, Hashimoto H, Enjoji M. Benign schwannoma of the gastrointestinal tract: a clinicopathologic and immunohistochemical study. Hum Pathol. 1988 Mar;19(3):257-64.

5 McMenamin ME, Fletcher CD. Expanding the spectrum of malignant change in schwannomas: epithelioid malignant change, epithelioid malignant peripheral nerve sheath tumor, and epithelioid angiosarcoma: a study of 17 cases. Am J Surg Pathol. 2001 Jan;25(1):13-25.

6 Matsumoto T, Yamamoto S, Fujita S, Akasu T, Moriya Y. Cecal schwannoma with laparoscopic wedge resection: report of a case. Asian J Endosc Surg. 2011 Nov;4(4):178-80.

7 Maciejewski A, Lange D, Włoch J. Case report of schwannoma of the rectum—clinical and pathological contribution. Med Sci Monit. 2000 Jul-Aug;6(4):779-82.

8 Inagawa S, Hori M, Shimazaki J, Matsumoto S, Ishii H, Itabashi M, et al. Solitary schwannoma of the colon: report of two cases. Surg Today. 2001;31(9):833-8.

9 Nonose R, Lahan AY, Santos Valenciano J, Martinez CA. Schwannoma of the Colon. Case Rep Gastroenterol. 2009 Sep;3(3):293-9.

10 Tashiro Y, Matsumoto F, Iwama K, Shimazu A, Matsumori S, Nohara S, et al. Laparoscopic resection of schwannoma of the ascending colon. Case Rep Gastroenterol. 2015 Jan;9(1):15-9.

11 Bugiantella W, Rondelli F, Mariani L, Peppoloni L, Cristallini E, Mariani E. Schwannoma of the colon: A case report. Oncol Lett. 2014 Dec;8(6):2511-2.

12 Tsunoda C, Kato H, Sakamoto T, Yamada R, Mitsumaru A, Yokomizo H, et al. A case of benign schwannoma of the transverse colon with granulation tissue. Case Rep Gastroenterol. 2009 Apr;3(1):116-20.

13 Kim G, Kim SI, Lee KY. Case Report: Schwannoma of the sigmoid colon: a case report of a rare colonic neoplasm and review of literature. F1000 Res. 2019 May;8:652.

14 Miettinen MM, Antonescu CR, Fletcher CD, Kim A, Lazar AJ, Quezado MM, et al. Histopathologic evaluation of atypical neurofibromatous tumors and their transformation into malignant peripheral nerve sheath tumor in patients with neurofibromatosis 1-a consensus overview. Hum Pathol. 2017 Sep;67:1-10.

15 Baek SJ, Hwangbo W, Kim J, Kim IS. A case of benign schwannoma of the ascending colon treated with laparoscopic-assisted wedge resection. Int Surg. 2013 Oct-Dec;98(4):315-8. 
Case Reports in Gastroenterology
Case Rep Gastroenterol 2020;14:483-490

DOI: $10.1159 / 000509542$

(c) 2020 The Author(s). Published by S. Karger AG, Basel www.karger.com/crg

Kojima et al.: A Case of Ascending Colon Schwannoma
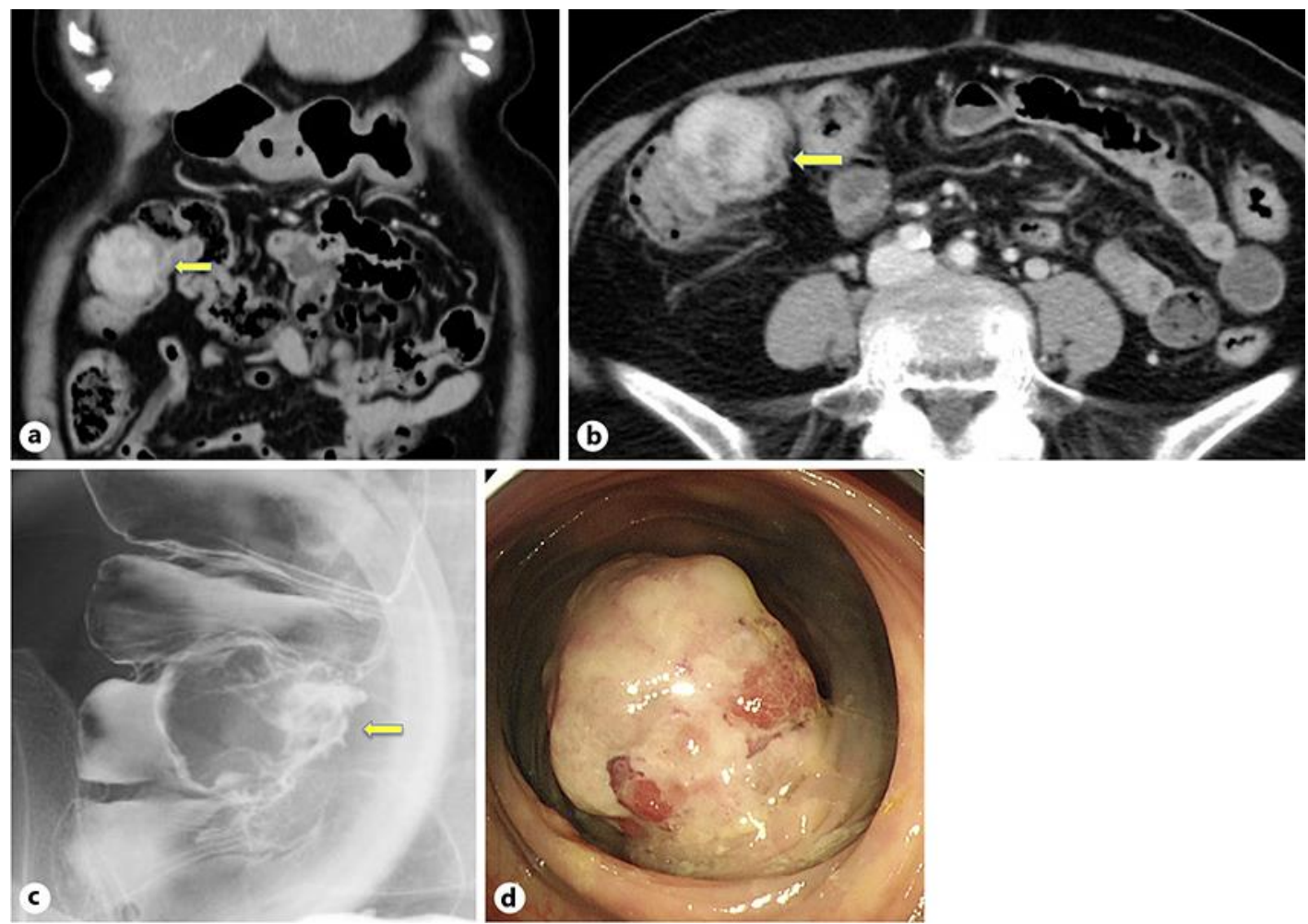

Fig. 1. Preoperative diagnostics. Abdominal computed tomography axial (a) and coronal (b) slices revealed a tumor in the ascending colon with a high-density area and a size of $3 \mathrm{~cm}$. c Contrast enema images revealed a steep-edged mass shadow in the ascending colon with clearly defined boundaries. $\mathbf{d}$ Colonoscopy revealed a rough mass at the ascending colon that was covered by a white coat, with erosions spreading all over the tumor. 


\section{Case Reports in Gastroenterology}
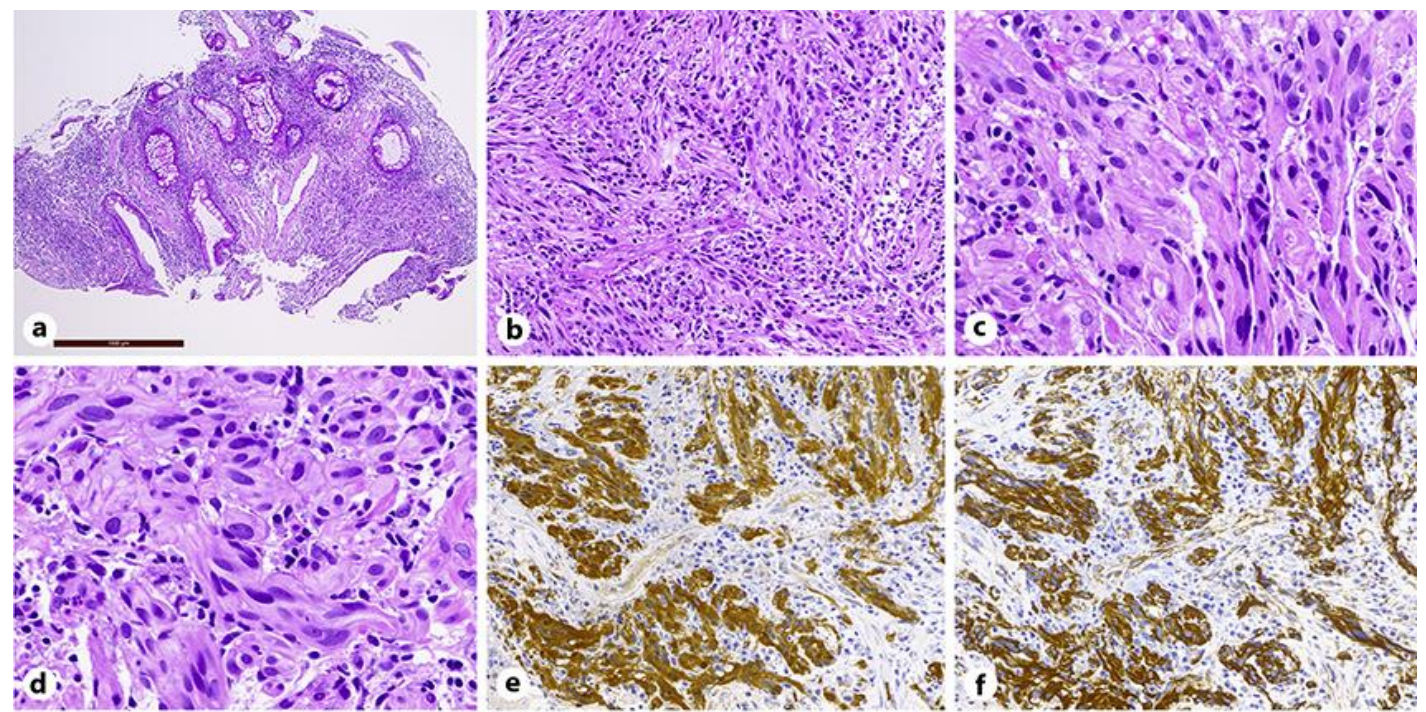

Kojima et al.: A Case of Ascending Colon Schwannoma

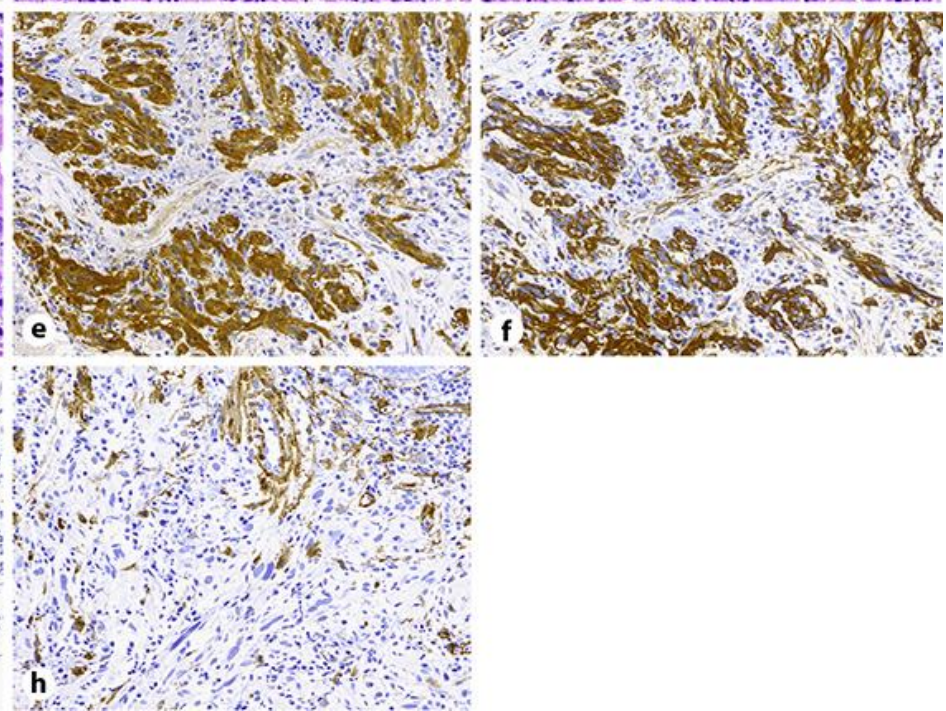

Fig. 2. Biopsy specimen analysis. a Bar: $1,000 \mu \mathrm{m}$. Inflamed erosive colon mucosa with spindle cell proliferation in the deeper lamina propria region containing woven nests of compact bundles of slender, wavy spindle cells admixed with a lymphocyte-rich stroma. $\mathbf{b}$-d The spindle cells also formed compact fascicles, occasionally aligning in rows. Individual cells had a distinct eosinophilic cytoplasm and dark fusiform nuclei that varied in shape and size (hematoxylin and eosin stain). b Original magnification: 1:100. c, d Original magnification: 1:400. e All spindle-shaped tumor cells were strongly and globally positive for S100 protein, with both nuclear and cytoplasmic staining. Original magnification: 1:200. f Vimentin was also strongly expressed. Original magnification: 1:200. $\mathbf{g}$, $\mathbf{h}$ Tumor cells were negative for CD117 (KIT) and smooth muscle-related antigens (smooth muscle actin, desmin, calponin, and h-caldesmon). $\mathbf{g}$, $\mathbf{h}$ Original magnification: $1: 200$. 


\section{Case Reports in Gastroenterology}

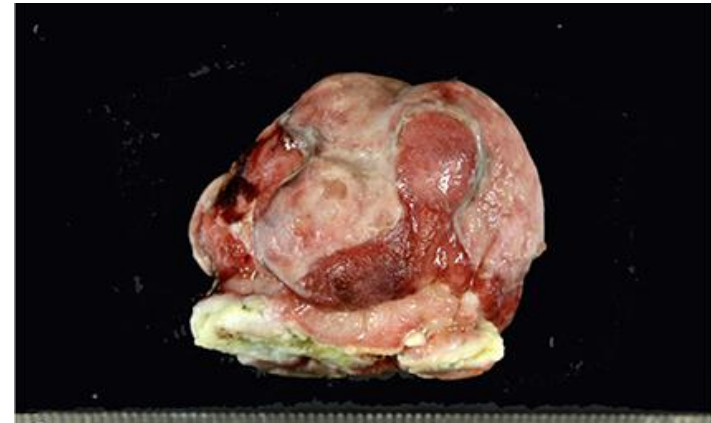

(a)

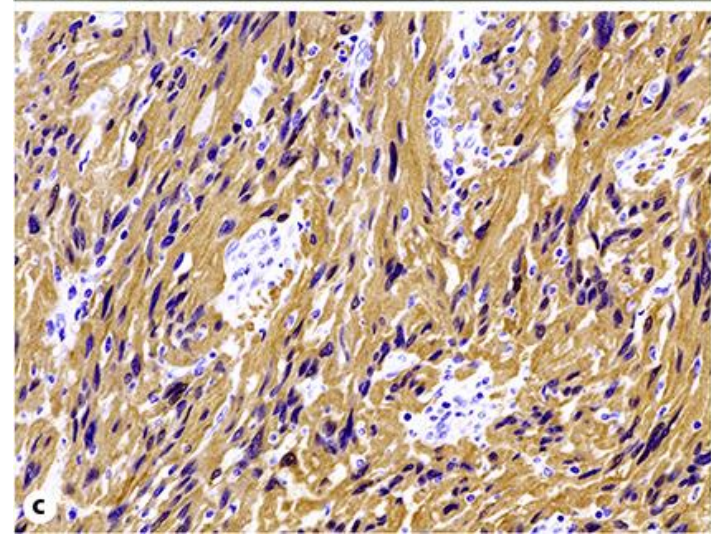

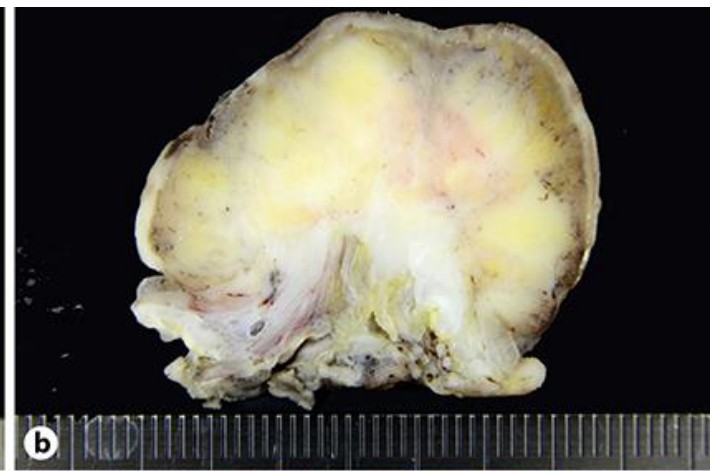

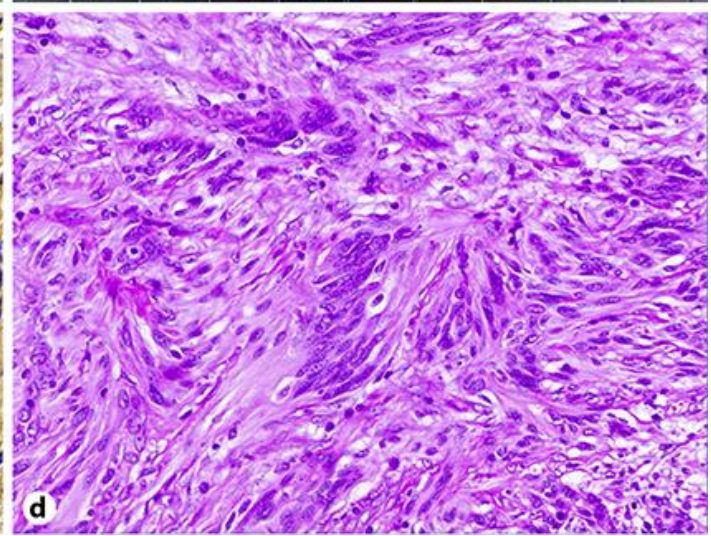

Fig. 3. Resected specimen analysis. a Gross inspection revealed a circumscribed but unencapsulated ovoid nodular mass with a polypoid intraluminal component, measuring $3 \times 3 \times 1.7 \mathrm{~cm}$ in size. Wide-spread mucosal erosion was grossly visible. $\mathbf{b}$ The cut surface was yellowish without myxoid degeneration or tumor necrosis. The surface revealed that the muscle layer was infiltrated by the tumor. c S100 protein was detected in the immunohistochemical analysis. Original magnification: 1:400. d Hematoxylin and eosin staining revealed that the spindle cells formed compact fascicles, occasionally aligning in rows. The findings were same as those for the biopsy specimens. Original magnification: 1:200. 